\title{
Chitosan-The Application of a Natural Polymer against Iron Hydroxide Deposition
}

\author{
Simona Schwarz ${ }^{1}$, Christine Steinbach ${ }^{1}$, Dana Schwarz ${ }^{2}$, Mandy Mende ${ }^{1}$, Regine Boldt ${ }^{1}$ \\ ${ }^{1}$ Leibniz-Institut für Polymerforschung Dresden e.V., Dresden, Germany \\ ${ }^{2}$ Department of Organic Chemistry, Faculty of Science, Charles University in Prague, \\ Prague, Czech Republic \\ Email: "simsch@ipfdd.de
}

Received 17 June 2016; accepted 7 August 2016; published 10 August 2016

Copyright (C) 2016 by authors and Scientific Research Publishing Inc.

This work is licensed under the Creative Commons Attribution International License (CC BY). http://creativecommons.org/licenses/by/4.0/

(c) (i) Open Access

\begin{abstract}
As a consequence of mining, heavy metal ions can be exposed to the environment hence contaminate ground water and surface water amongst others. The natural polymer chitosan was proved to be an excellent adsorber material for the effective removal of iron and sulfate ions in batch as well as in column experiments. The adsorption behavior of iron ions, as well as sulfate ions was investigated by utilizing chitosan flakes as a natural adsorbent. The removal was studied using adsorbance measurements, SEM and SEM-EDX. The adsorption capacity of chitosan was determined at different times. The received adsorption capacities for iron ions were very promising with a maximum adsorption capacity of $85 \mathrm{mg} / \mathrm{g}$ and a rate of separation of $100 \%$. The maximum adsorption capacity obtained for sulfate ions was $188.8 \mathrm{mg} / \mathrm{g}$ and a rate of $80 \%$.
\end{abstract}

\section{Keywords}

Chitosan, Adsorption of Iron- and Sulfate Ions, Iron hydroxide Deposition

\section{Introduction}

Since approximately 100 years, brown coal is demounted in different region of Germany. Because the decommissioning and flooding of many open pit mining the groundwater increase, iron salts and iron hydroxide are washed out from tipping areas as well as from naturally occurring pyrite layers. This leads to a considerable pollution of the surface water (i.e. iron hydroxide deposition) and causes problems with the drinking water abstraction due to the high iron concentration accordingly [1]-[3]. The influences of the heavy metal ion pollution in waters are already observable. The deterioration of flora and fauna as well as of the constructions in water is

\footnotetext{
*Corresponding author.
}

How to cite this paper: Schwarz, S., Steinbach, C., Schwarz, D., Mende, M. and Boldt, R. (2016) Chitosan-The Application of a Natural Polymer against Iron Hydroxide Deposition. American Journal of Analytical Chemistry, 7, 623-632. 
significant. The issue of the iron entry into the waters increases in the case of decommissioning of the open brown coal pit and the flooding of the abandoned open pit due to an increasing groundwater level and decreasing groundwater depression cones [4] [5]. Thus, the demand of removing the iron and sulfate ions in water increases due rising corrosion of cement and steel constructions and the thereby increasing requirement of reconstruction. The effect of an opencast pit and ensuing iron hydroxide deposition of the waters illustrates an issue in many parts of the world and has been therefore highlighted as a relevant topic and problem statement in Science in the year 2014 already [6].

In waste water treatment, traditional coagulation and flocculation processes are suitable. Inorganic flocculants (e.g. aluminum hydroxide, or iron chloride) as well as synthetic water soluble polymers (i.e. polyelectrolytes such as polyacrylamide for example), or natural polymer (e.g. starch, or chitosan) are used [7]-[13]. However, the application of such flocculants does not always lead to an efficient removal. Heavy metal ions can be harmful for humans and aquatic life in the ppb range already. Additionally, the $\mathrm{pH}$ in the watercourse changes if only the positively charged heavy metal ions are removed. The remaining anions (e.g. chloride, or sulfate) lead to further problems in the water system due to the increasing acidity.

Furthermore, adsorbents such as activated carbon or ion exchange resins are used for the treatment of waters and waste water. Synthetic adsorbents exhibit high adsorption capacities having the disadvantage of high production costs [14].

For this reason, the quest for effective and cost-efficient adsorbents for heavy metal ions has become a major topic in research during the last years. Industrial waste products mainly arising from agriculture are potentially interestingly adsorber materials due to their high abundance. These kinds of adsorber materials are many called biopolymers [15] [16].

Chitin and its deacetylated derivate chitosan are two kinds of biopolymers (i.e. polysaccharides) which are obtained from crustacean shells and exhibit the capability of adsorbing a multiplicity of heavy metal ions. The strong affinity for heavy metal ions is attributed to the high impact of nitrogen in the polymer matrix in the form of primary amino groups. The capabilities of chitosan are sufficiently established in literature [17]-[21]. However, the application fails due to insufficient chain lengths and the flocculation stability for operating Chitosan as a flocculation agent as well as the relatively high price. For the industrial commitment, relatively constant and similar reproducible utilization properties to synthetic polymers are of high importance. Nevertheless, industry is not willing to pay a higher price for those products despite excellent environmental properties. In case of applying chitosan as a flocculation agent, the cost factor is compensated by the minor amount of one thirds in comparison with synthetic polymers reaching similar properties.

The adsorption properties of chitosan as adsorber material were investigated in batch and column experiments with respect to the binding mechanism of the heavy metal ions. Up to our knowledge, this is the first publication focusing on the adsorption potential of cation and anions simultaneously.

The adsorption properties of chitosan with respect to the anion sulfate and the cation iron were analyzed. The adsorption process was investigated in dependence of time and concentration of the two ions. The two contrary charged ions were examined as iron sulfate and for comparison as sulfuric acid without the influence of the iron ion in solution. The results can be outlined as:

- Adsorption isotherm of iron sulfate and sulfate on chitosan, respectively.

- SEM-EDX measurements of pure chitosan in comparison with chitosan after the adsorption process.

SEM-EDX measurements shall contribute the understanding of the adsorption mechanism of both contrary charged ions on the surface.

\section{Experimental}

Chitosan in form of powder or flakes with a deacetylation degree of 90\% (product name Ch90/200/A1) from the company BioLogHeppe GmbH were used for the experiments. The chitosan powder exhibited a $\mathrm{D}_{50}$ value of $200 \mu \mathrm{m}$ obtained by laser diffraction measurements in deionised water. Chitosan flakes possessed a broad particles size distribution within the mm range. All investigations were performed in batch and column experiments. The iron(II) concentrations of the iron sulphate solutions varied between $0.04 \mathrm{mg} / \mathrm{L}$ and $1300 \mathrm{mg} / \mathrm{L}$. Sulfuric acid was used with a concentration of $0.9 \mathrm{~g} / \mathrm{L}$ and $0.5 \mathrm{~g} / \mathrm{L}$ with a resulting $\mathrm{pH}$ value 2.02 and 2.25 respectively. $30 \mathrm{~mL}$ of the diluted sulphuric acid solutions were added to $0.1 \mathrm{~g}$ of chitosan for the batch experiments at r.t. The concentration of the iron sulphate solutions were $1 \mathrm{~g} / \mathrm{L}$ for the batch experiments. The adsorption time $\left(\mathrm{t}_{\mathrm{ads}}\right)$ 
of the experiments was 24 hours hence within the adsorption equilibrium. Additionally has the adsorption time been varied by constant salt concentration to determine the adsorption equilibrium.

The assignment of the heavy metal and anion concentration in solution was carried out with a DR6000 spectrophotometer from the company HACH Lange GmbH, Germany. The DR6000 microprocessor controlled spectrophotometer with a reference beam and a wave length region of 190 to $900 \mathrm{~nm}$. The instrument is appropriate for routine analysis and distinct applications (programmable). Particular associated cuvette tests for each ion are provided from the company. The instrument recognizes the specific cuvette test with a bar code on each standardized cuvette.

\section{Results and Discussion}

Chitosan exhibited excellent results as a flocculation agent in previous examinations already [22]. In this work, chitosan has been investigated as a solid adsorber material in form of powder and flakes for the removal of iron and sulphate ions. Figure 1 presents the adsorption of iron sulphate on chitosan powder in batch experiments. The adsorption time has been varied for the initial concentrations of $0.1 \mathrm{~g} / \mathrm{L}$ and $1 \mathrm{~g} / \mathrm{L}$ of iron sulphate. Chitosan as a white adsorber material tends to be colored after the adsorption process depending on the specificcolor of the heavy metal salt [17]. The intensity of the coloration is always dependent on the initial concentration of the metal salt and the adsorption time. However, in case of iron sulphate the resulting color of the chitosan material is rather rust brown instead of pale green after the adsorption process in the batch experiments. One possible explanation is the oxidation of the iron(II) ions to iron(III) ions before the adsorption on chitosan due to atmospheric oxygen in the water. Hence, the iron is rather adsorbed as iron(III) oxide or iron(III) oxide-hydroxide. The intensity of the coloration increases with increasing adsorption time as well as with an increasing ion concentration at constant adsorption time $\left(\mathrm{t}_{\mathrm{ads}}=24 \mathrm{~h}\right)$.

In Scheme 1, the proposed adsorption mechanism of the iron sulfate ions on the chitosan surface is displayed. For a high content of atmospheric oxygen in water, iron(II) gets easily oxidized in solution to iron(III) oxide and iron(III) oxide-hydroxide. This is manly the case for the batch experiments were the chitosan flakes were stirred with the solution in an open baker. Hence, iron(II) and iron(III) oxide is concurrently adsorbed on the chitosan surface. The content of atmospheric oxygen seems to be lower for the column experiments leading to a higher adsorption of iron sulfate on the chitosan surface. However, a quantitative statement about the two possible iron species on the chitosan surface will be an important consideration in our nearby investigations.

\subsection{Adsorption Isotherm of Iron Sulfate on Chitosan}

The adsorption efficiency of iron(II) ions on chitosan powder and flakes is displaced in Figure 2. Besides the morphology of chitosan material were two initial concentrations examined in dependence of the adsorption time.

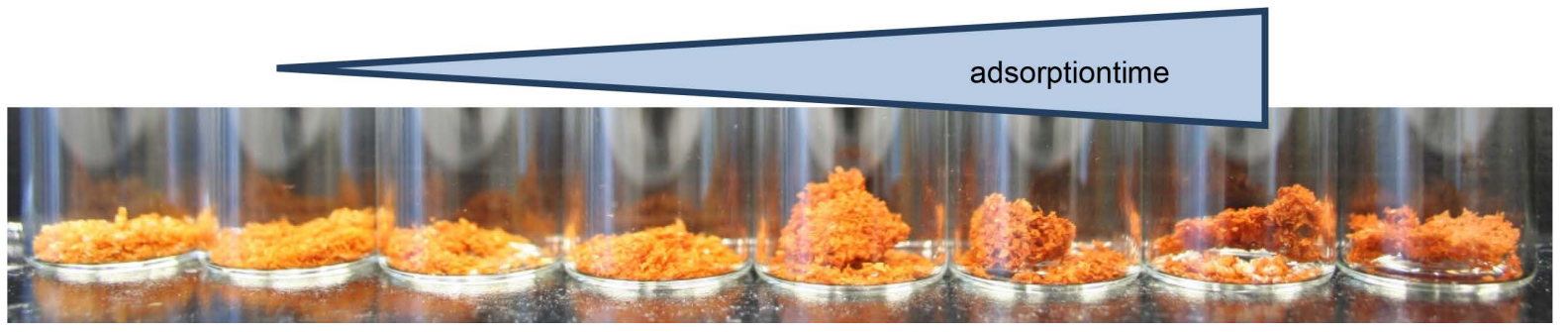

Figure 1. Adsorption of iron sulfate on chitosan powder; $1.0 \mathrm{~g} / \mathrm{L}$ iron sulfate, with increasing adsorption time from left to right hand side.



Scheme 1. Schematic diagram of the adsorption mechanism of iron sulfate on chitosan. 
The adsorption equilibrium for the adsorption of iron and sulfate ions has been reached after 24 hours.

In general, sulfate ions were less adsorbed than iron ions. After 24 hours, $99 \%\left(\mathrm{C}_{\mathrm{eq}} / \mathrm{c}_{0}=0.01\right)$ of the iron ions were adsorbed in comparison with an adsorption efficiency of only $60 \%\left(\mathrm{c}_{\mathrm{eq}} / \mathrm{c}_{0}=0.4\right)$ of the sulfate ions. Previous adsorption investigations of copper sulfate on chitosan showed an adsorption ratio of 1:1 for the two contrary charged ions [17]. In the case of iron sulfate has the additional oxidation step of iron(II) to iron(III) oxide be taken into account. Hence, adsorption sites on the chitosan surface are blocked by the iron(III) oxide leading to a less efficient adsorption of the sulfate ion. In summary, the adsorption of iron(III) oxide as well as iron(II) sulfate on the chitosan surface is assumed to take place.

Figure 3 shows the adsorption capacities of iron ions on chitosan flakes after an adsorption time of 24 hours. The adsorption capacity q of the iron ions was calculated with the following equation:



Figure 2. Adsorption of $\mathrm{FeSO}_{4}$ on chitosan (powderand flakes) in dependence of the adsorption time, $\mathrm{c}_{0 \mathrm{FeSO}}=1.0 \mathrm{~g} / \mathrm{L}$, each with $0.1 \mathrm{~g}$ chitosan and $30 \mathrm{~mL}$ solution.

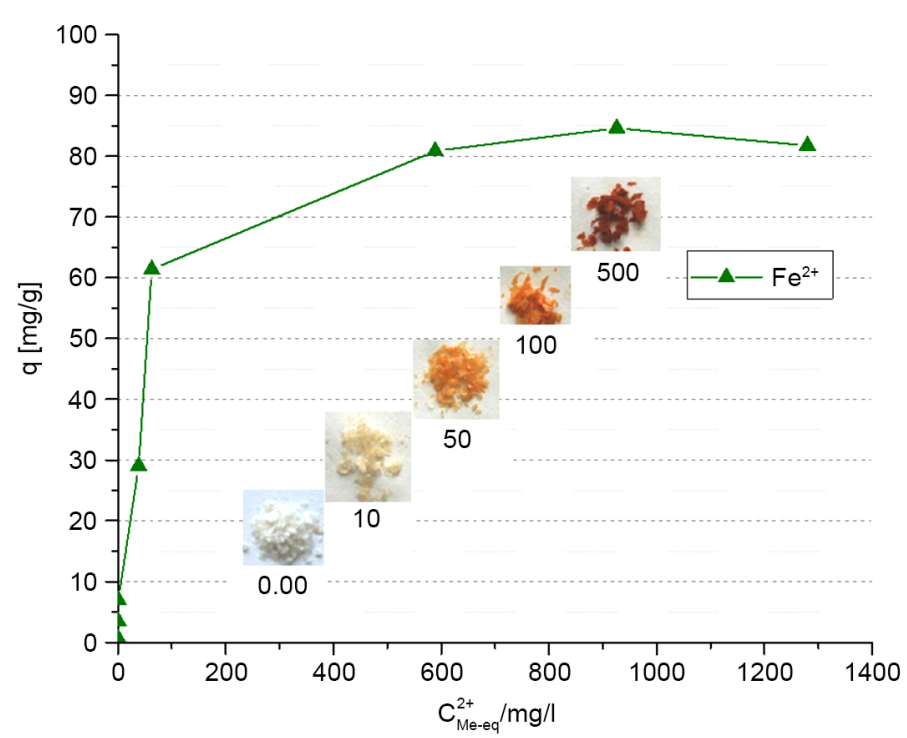

Figure 3. Adsorption of $\mathrm{FeSO}_{4}$ on chitosan flakes in dependence of the iron(II) ion concentration $\mathrm{c}_{\mathrm{e}}$; adsorption time $24 \mathrm{~h}$, each with $0.1 \mathrm{~g}$ chitosan and $30 \mathrm{~mL}$ salt solution, beneath images of the chitosan flakes after the adsorption process. 


$$
\mathrm{q}=\frac{\left(\mathrm{c}_{0}-\mathrm{c}_{\mathrm{e}}\right) \mathrm{V}}{\mathrm{m}}
$$

where $\mathrm{c}_{0}$ is the initial concentration of the metal ion (Fe(II) ions) in solution, $\mathrm{C}_{\mathrm{e}}$ is the metal ion concentration at equilibrium, $\mathrm{V}$ is the volume of the metal salt solution, and $\mathrm{m}$ the mass of the adsorbent.

The maximum adsorption capacity of iron ions on chitosan flakes is $85 \mathrm{mg} / \mathrm{g}$. In comparison, chitosan powder exhibits a higher adsorption capacity due to larger surface area.

\subsection{Adsorption of Sulfate Ions on Chitosan}

Sulfate ions should undergo a strong interaction with the chitosan surface based on the protonated amine functionality. Therefore, the adsorption of diluted sulfuric acid on chitosan powder has been investigated (s. Figure 4). The adsorption of the sulfate ions was examined with two different initial concentrations, $0.5 \mathrm{~g} / \mathrm{L}$ and $0.9 \mathrm{~g} / \mathrm{L}$. The adsorption study with a $0.5 \mathrm{~g} / \mathrm{L}$ sulfate solution resulted in an adsorption efficiency of $80 \%$ means a ratio $\mathrm{c}_{\mathrm{eq}} / \mathrm{c}_{0}=0.2$. This correlates to a removal of $188 \mathrm{mg} / \mathrm{g}$. For the experiments with a nearly twice as high initial concentration of sulfate $(0.9 \mathrm{~g} / \mathrm{L})$ was an adsorption efficiency of $68 \%\left(\mathrm{C}_{\mathrm{eq}} / \mathrm{c}_{0}=0.32\right)$ and hence a removal of $166 \mathrm{mg} / \mathrm{g}$ obtained. The relatively high adsorption efficiency for $0.9 \mathrm{~g} / \mathrm{L}$ initial sulfate concentration in comparison $0.5 \mathrm{~g} / \mathrm{L}$ can be explained by the $\mathrm{pH}$ difference in solution. The $\mathrm{pH}$ values were measured before and after each experiment and are summarized in Table 1.

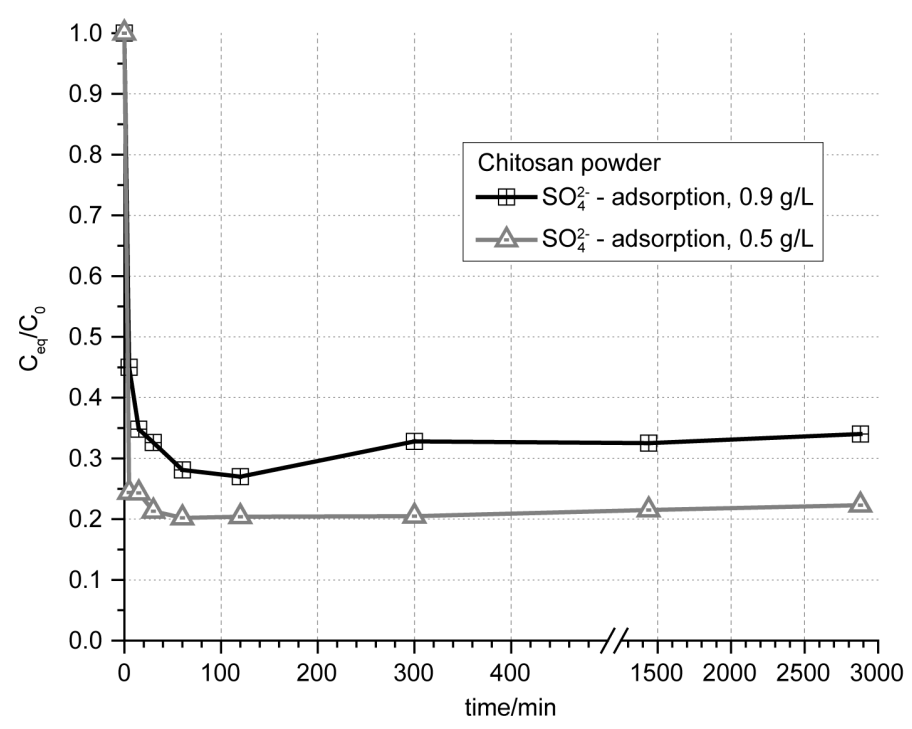

Figure 4. Adsorption of sulfuric acidon chitosan flakes in dependence of the adsorption time; two initial concentrations of diluted sulfuric acid were examined with a constant amount of $0.1 \mathrm{~g}$ chitosan and 30 $\mathrm{mL}$ solution which had to be examined for each experiment. The corresponding $\mathrm{pH}$ values before and after each adsorption experiment are shown in Table 1.

Table 1. Adsorption of $\mathrm{H}_{2} \mathrm{SO}_{4}$-solutionon chitosan (Ch90/200/A1), with each $0.1 \mathrm{~g}$ chitosan and $30 \mathrm{~mL}$ solution.

\begin{tabular}{|c|c|c|c|c|c|}
\hline \multirow[b]{2}{*}{ Sample } & \multicolumn{2}{|c|}{ pH-value } & \multicolumn{2}{|c|}{$\mathrm{SO}_{4}^{2-}$ content } & \multirow[b]{2}{*}{ Max. adsorption } \\
\hline & $\begin{array}{c}\text { Before } \\
\text { adsorption }\end{array}$ & $\begin{array}{c}\text { After } \\
\text { adsorption }\end{array}$ & $\begin{array}{l}\text { Before } \\
\text { adsorption }\end{array}$ & $\begin{array}{c}\text { After } \\
\text { adsorption }\end{array}$ & \\
\hline $0.9 \mathrm{~g} / \mathrm{L}(\stackrel{\wedge}{=} 0.092 \%)$ & 2.02 & 2.77 & $\begin{array}{c}853 \mathrm{mg} / \mathrm{L} \\
\left(\hat{=} \mathrm{m}_{\mathrm{A}} / \mathrm{m}_{\mathrm{C}}{ }^{* *} 256 \mathrm{mg} / \mathrm{g}\right)\end{array}$ & $\begin{array}{c}240 \mathrm{mg} / \mathrm{L} \\
\left(\hat{=} \mathrm{m}_{\mathrm{A}} / \mathrm{m}_{\mathrm{C}}^{* *} 189 \mathrm{mg} / \mathrm{g}\right)\end{array}$ & $73 \%$ \\
\hline $0.5 \mathrm{~g} / \mathrm{L}(\stackrel{=}{=} 0.051 \%)$ & 2.25 & 5.40 & $\begin{array}{c}511 \mathrm{mg} / \mathrm{L} \\
\left(\stackrel{=}{=} \mathrm{m}_{\mathrm{A}} / \mathrm{m}_{\mathrm{C}}^{* *} 153 \mathrm{mg} / \mathrm{g}\right)\end{array}$ & $\begin{array}{c}100 \mathrm{mg} / \mathrm{L} \\
\left(\bumpeq \mathrm{m}_{\mathrm{A}} / \mathrm{m}_{\mathrm{C}}^{* * *} 125 \mathrm{mg} / \mathrm{g}\right)\end{array}$ & $79 \%$ \\
\hline
\end{tabular}

"at the adsorption maximum; ${ }^{* *} \mathrm{~mA} / \mathrm{mC}^{* *}$ : ratio mass anion/mass chitosan. 


\subsection{SEM-EDX Measurements of Pure Chitosan in Comparison with Chitosan after the Adsorption Process}

Furthermore, the adsorption analysis was supported by SEM images of untreated chitosan powder and flakes as well as after the adsorption process to get a better understanding of the adsorption mechanism. Figure 5 displays the SEM images of pure chitosan flakes before the adsorption process. In comparison, Figure 6 represents chitosan after the adsorption of the salt leading to significant changes of the surface character observed by SEM.

Figure 6 represents SEM images of chitosan flakes after the adsorption process of iron sulfate in dependence of the adsorption time (Figure 6(a)) and the initial concentration of the heavy metal salt (Figure 6(b)). Analogue results were obtained for chitosan powder.

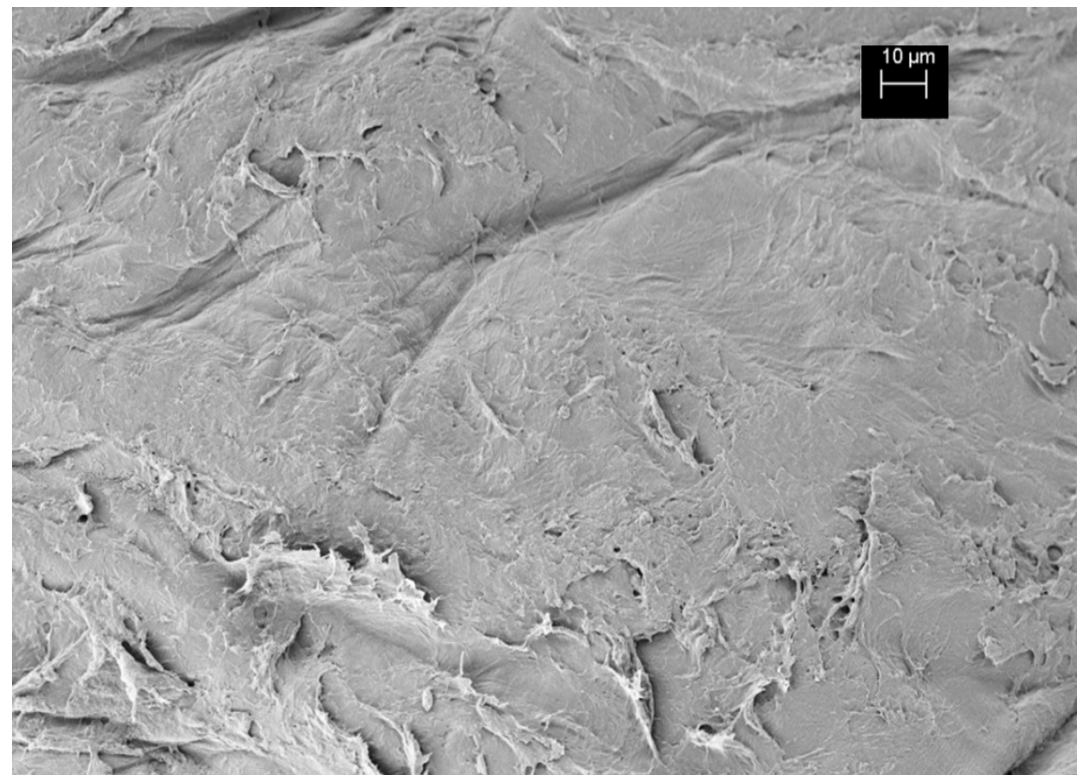

Figure 5. SEM image of untreated chitosan flakes (with $3 \mathrm{~nm}$ Pt sputtered layer on it, magnification from left to right hand side: $500 \times$ ).

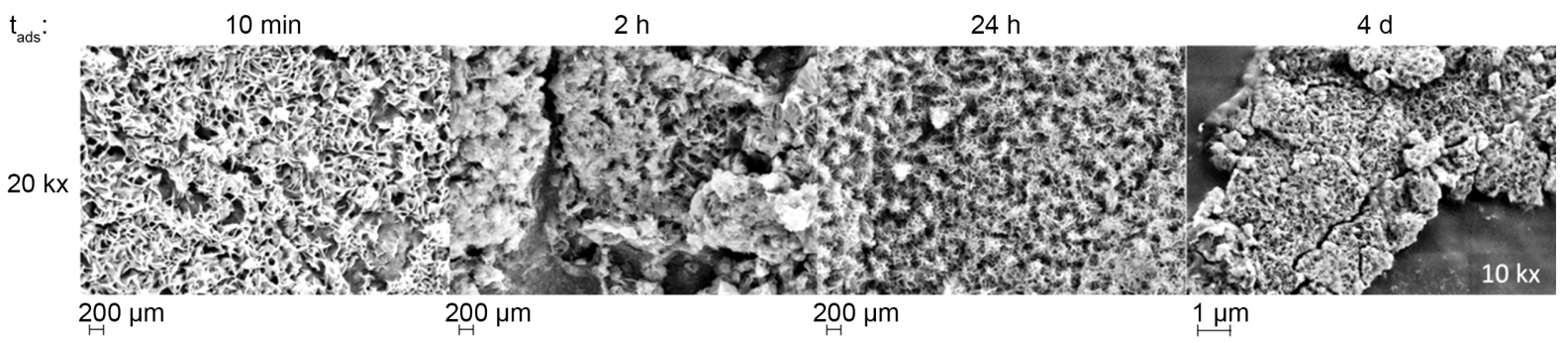

(a)

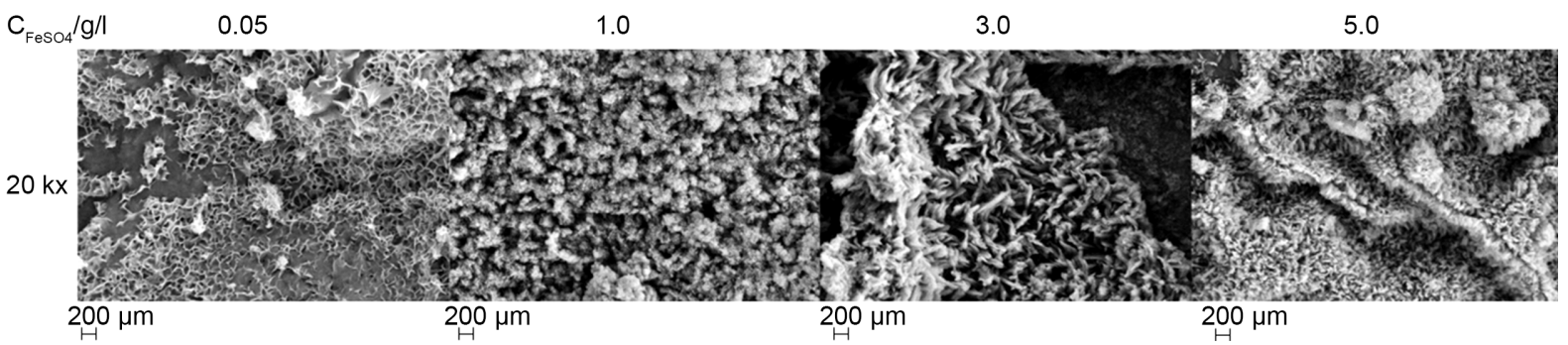

(b)

Figure 6. SEM images of chitosan flakes after the adsorption of Fe(II) ions, (a) variation of the adsorption time, $\mathrm{C}_{0 \mathrm{FeSO}}{ }_{4}=$ $0.5 \mathrm{~g} / \mathrm{L}$, and (b) variation of the Fe(II) ion concentration, adsorption time of $24 \mathrm{~h}$. 
On the surface of the chitosan flakes can be crystal like structures observed arising from the adsorption of the iron sulfate salt. The initial concentration of iron sulfate varied from $0.05 \mathrm{~g} / \mathrm{L}, 1.0 \mathrm{~g} / \mathrm{L}, 3.0 \mathrm{~g} / \mathrm{L}$, and $5.0 \mathrm{~g} / \mathrm{L}$ (from left to right hand side in Figure 6(b)). The crystal like structure becomes more observable and more distinct in volume with increasing initial concentration of the metal salt. The size of the crystals even leads to peel off from the chitosan surface at higher concentrations.

The SEM image of chitosan after the adsorption process with the corresponding elemental distribution of Fe and S from EDX measurements can be seen in Figure 7. At a relatively low initial salt concentration of $0.1 \mathrm{~g} / \mathrm{L}$ the crystal like structures appear in acicular structure. The elemental distribution mapping of chitosan before and after the adsorption of the salt reveals the expected element Fe as well as the element $\mathrm{S}$ after the adsorption process. In general, the elements possess a relatively equal distribution on the surface. In summary, an adsorption mechanism via crystallization on the surface of chitosan is expected. Therefore, chitosan can bind substantially more iron on the surface due to the crystal nucleation.

However, for iron sulfate an equal elemental distribution can only be observed for sulfur (see Figure 7(b)). In contrast, iron appears mainly concentrated on certain regions on the chitosan surface. This fact gives evidence to a predominant adsorption of iron(III) in form of iron oxide or iron oxide-hydrate rather than iron(II) takes place. Iron gets easily oxidized by the atmospheric oxygen in the water.

Additionally to the batch studies, adsorption investigations in the column were performed. Chitosan flakes was packed into a column and treated with an iron sulfate solution. Iron sulfate solution was transported through column at a speed of $80 \mathrm{U} / \mathrm{min}$ by a peristaltic pump. The solution leaving the column was collected and analyzed regarding the changes in sulfate and iron concentration.

Similar to the batch experiments, a coloration of the chitosan in the column can be observed (see Figure 8). The intensity of the coloration is time dependent. The lower part of the column changes the color first towards the rust brown color which could already be noticed in the batch experiments before (see Figure 3). The dark

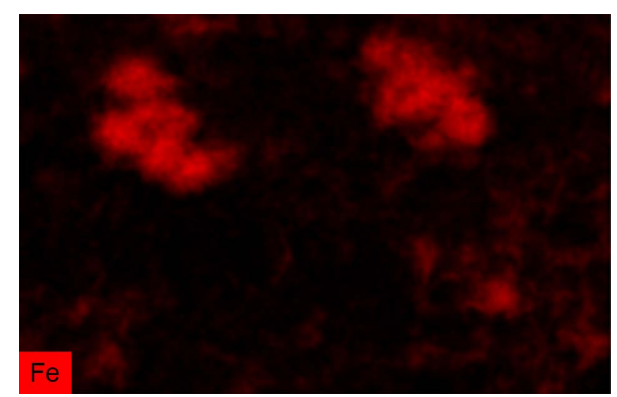

(a)



(b)

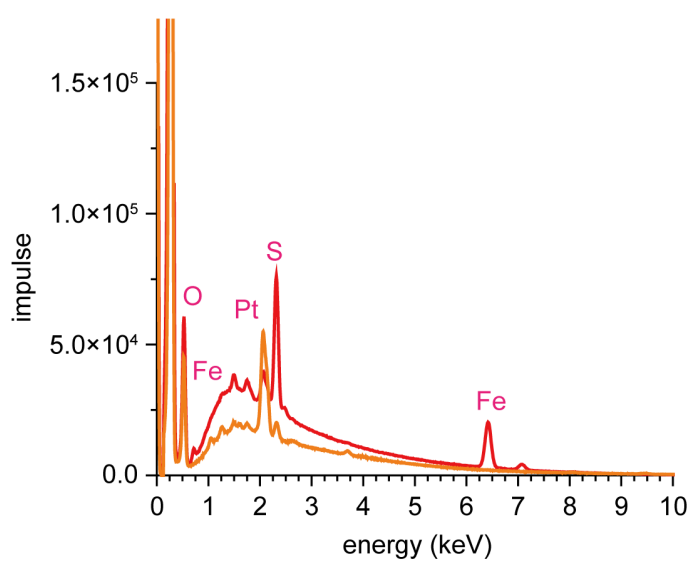

(c)

Figure 7. SEM/EDX investigations of the adsorption of iron ions on Ch90/200/A1 and the corresponding EDX pattern for Fe und $\mathrm{S}$ as well as the image of element distribution (a), (b). The initial concentration of $\mathrm{FeSO}_{4}$ was $\mathrm{C}_{0-\mathrm{FeSO}_{4}}=0.1 \mathrm{~g} / \mathrm{L}$, EDX spectra of untreated chitosan, as well as after the adsorption process (c). 
brown color is expected to arise due to the oxidation of the iron(II) ions to iron(III) oxide. On the upper part (in the direction of flow) of the column can the characteristic color of iron sulfate be observed. The separation two types of colors might be due to a gradient of atmospheric oxygen in the column. After an adsorption time of 3 hours, the column is completely colored. The color change as it can be seen in Figure 8 after 10 hours does not change even after leaving the column for several weeks at it is. This suggests to no further oxidation happening in the upper part of the column as the pale green color of the iron sulfate does not change to dark brown.

The ratio between the iron concentration in solution before and after the column experiment in dependence of the adsorption time is represented in Figure 9. Within the first 50 minutes, the iron ions are completely adsorbed in the column. Subsequently, the iron concentration rises until a plateau is reached after 3 hours. After 3 hours experiment time, the adsorption process is comparatively very slow but an intensification of the coloration of the column material can still be noticed. The experiment was stopped after 10 hours, although the adsorption process has not been completed by then.

Within the first hour of the column experiment, $100 \%$ of iron ions and $40 \%$ of sulfate ions were adsorbed. After 3 hours, minor amounts were adsorbed and a ratio for $\mathrm{c}_{\mathrm{eq}} / \mathrm{c}_{0}$ of 0.7 for iron (i.e. $30 \%$ of iron ions were adsorbed) and 0.8 for sulfate ions (i.e. $20 \%$ of sulfate ions were adsorbed) can be observed.

As the adsorption can manly be observed as a crystallization process on the surface of the chitosan material we want to improve the chitosan towards lower material costs in the successive investigations.



$0 \mathrm{~min}$



$10 \mathrm{~min}$

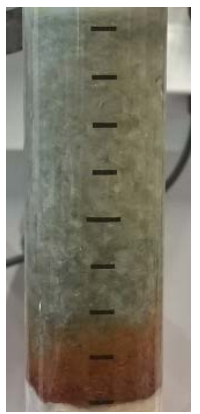

$3 \mathrm{~h}$

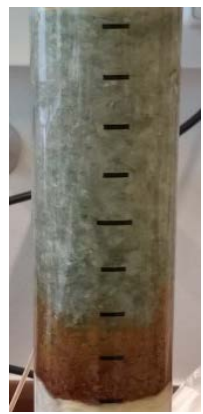

$10 \mathrm{~h}$

Figure 8. Images of the column experiments; column was filled by chitosan flakes and illustrated at proceeding adsorption time within the experiment.

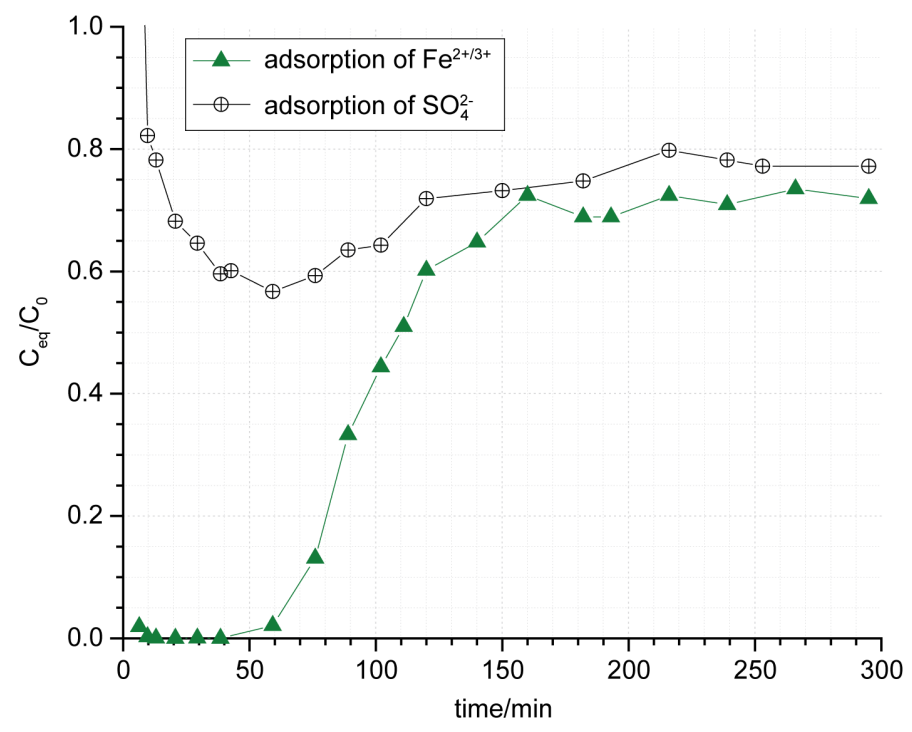

Figure 9. Adsorption of $\mathrm{FeSO}_{4}$ on chitosan flakes packed in a column in dependence on the adsorption time, $\mathrm{C}_{\mathrm{FFeSO}_{4}}=1 \mathrm{~g} / \mathrm{L}$, speed of the peristaltic pump: $80 \mathrm{U} / \mathrm{min}$. 


\section{Conclusion}

Chitosan as an adsorber material has the ability to adsorb the positively charged, as well as the negatively charged ion of a heavy metal salt. This study indicates the adsorption of sulfate, as well as of iron ions. In batch experiments, the removal of iron ions occurs almost completely and sulfate could be removed with an efficiency of $60 \%$. At initial concentrations of $1.0 \mathrm{~g} / \mathrm{L}$ iron sulfate, an adsorption time of 24 hours was necessary. On the basis of the coloration of the original white adsorber material towards dark brown, an oxidation of the iron(II) ions to iron(III) oxide was proposed. The oxidation occurs due to the atmospheric oxygen in the water. Hence, the adsorption mechanism is competitive of iron(II) sulfate and iron(III) oxide. Additionally, the adsorption of iron sulfate on chitosan was investigated in a column experiment. Similar to the batch experiments, iron could be removed by nearly $100 \%$ efficiency and $40 \%$ for sulfate ions. After 3 hours, a constant removal rate of $30 \%$ iron ions and $20 \%$ sulfate ions was achieved. Biopolymers like chitosan can be applied as non-hazardous substances.

\section{Acknowledgements}

The company BioLogHeppe GmbH is acknowledged for the supply of the chitosan powder and flakes applied in this investigation.

\section{References}

[1] Wiegleb, G., Bröring, U., Mrzljak, J. and Schulz, F. (2000) Nature Conservation in Post-Mining Landscapes. PhysikaVerlag, Heidelberg

[2] Johnston, D. (2008) Abandoned Mines and the Water Environment. Science project SC030136-41

[3] Landtag Brandenburg, LUGV, Veränderte Wasserqualität durch Braunkohletagebaue 2012.

[4] Dold, B. (2014) Evolution of Acid Mine Drainage Formation in Sulphidic Mine Tailings. Minerals, 4, 621-641. http://dx.doi.org/10.3390/min4030621

[5] Cummings, D.E., March, A.W., Bostick, B., Spring, S., Caccavo F., Fendorf, S. and Rosenzweig, R.F. (2000) Evidence for Microbial Fe(III) Reduction in Anoxic, Mining-Impacted Lake Sediments (Lake Coeur d'Alene, Idaho). Applied and Environmental Microbiology, 66, 154-162. http://dx.doi.org/10.1128/AEM.66.1.154-162.2000

[6] Pikaar, I., Sharma, K.R., Hu, S., Gernjak, W., Keller, J. and Yuan, Z. (2014) Reducing Sewer Corrosion through Integrated Urban Management. Science, 345, 812-815. http://dx.doi.org/10.1126/science.1251418

[7] Genest, S., Petzold, G. and Schwarz, S. (2015) Removal of Micro-Stickies from Model Wastewaters of the Paper Industry by Amphiphilic Starch Derivatives. Colloids and Surfaces A: Physicochemical and Engineering Aspects, 484, 231-241. http://dx.doi.org/10.1016/j.colsurfa.2015.08.002

[8] Bratskaya, S., Genest, S., Petzold-Welcke, K., Heinze, T. and Schwarz, S. (2014) Flocculation Efficiency of Novel Amphiphilic Starch Derivatives: A Comparative Study. Macromolecular Materials and Engineering, 299, 722-728. http://dx.doi.org/10.1002/mame.201300277

[9] Schwarz, S. and Petzold, G. (2014) Polyelectrolyte Complexes in Flocculation Applications. Advances in Polymer Science, 256, 25-65.

[10] Rojas, R., Schwarz, S., Heinrich, G., Petzold, G., Schütze, S. and Bohrisch, J. (2010) Flocculation Efficiency of Novel Amphiphilic Starch Derivatives: A Comparative Study. Carbohydrates Polymers, 81, 317-322. http://dx.doi.org/10.1016/j.carbpol.2010.02.010

[11] Bratskaya, S., Schwarz, S., Petzold, S., Liebert, T. and Heinze, T. (2006) Cationic Starches of High Degree of Functionalization: 12. Modification of Cellulose Fibers toward High Filler Technology in Papermaking. Industrial \& Engineering Chemistry Research, 45, 7374-7379. http://dx.doi.org/10.1021/ie060135z

[12] Schwarz, S. and Petzold, G. (2006) Polyelectrolyte Interactions with Inorganic Particles. In: Somasundaran, P., Ed., Encyclopedia of Surface and Colloid Science, Vol. 6, CRC Press, Boca Raton, 4735-4754.

[13] Bratskaya, S., Avramenko, V., Schwarz, S. and Philippova, I. (2006) Enhanced Flocculation of Oil-in-Water Emulsions by Hydrophobically Modified Chitosan Derivatives. Colloids and Surfaces A: Physicochemical and Engineering Aspects, 275, 168-176. http://dx.doi.org/10.1016/j.colsurfa.2005.09.036

[14] Bailey, S.E., Olin, T.J., Bricka, R.M. and Adrian, D.D. (1999) A Review of Potentially Low-Cost Sorbents for Heavy Metals. Water Research, 33, 2469-2479. http://dx.doi.org/10.1016/S0043-1354(98)00475-8

[15] Huang, L., Xiao, C. and Chen, B. (2011) A Novel Starch-Based Adsorbent for Removing Toxic Hg(II) and Pb(II) Ions from Aqueous Solution. Journal of Hazardous Materials, 192, 832-836. 
http://dx.doi.org/10.1016/.j.jhazmat.2011.05.094

[16] O’Connell, D.W., Birkinshow, C. and O’Dwyer, T.F. (2006) A Modified Cellulose Adsorbent for the Removal of Nickel(II) From Aqueous Solutions. Chemical Technology and Biotechnology, 81, 1820-1828. http://dx.doi.org/10.1002/jctb.1609

[17] Rinauso, M. (2006) Chitin and Chitosan: Properties and Applications. Progress in Polymer Science, 31, 603-632. http://dx.doi.org/10.1016/j.progpolymsci.2006.06.001

[18] Muzzarelli, R.A.A., Jeunieux, C. and Gooday, G.W. (1985) Chitin in Nature and Technology. Plenum Press, New York.

[19] Guibal, E. (2004) Interactions of Metal Ions with Chitosan-Based Sorbents: A Review. Separation and Purification Technology, 38, 43-74. http://dx.doi.org/10.1016/j.seppur.2003.10.004

[20] Mende, M., Schwarz, D. and Schwarz, S. (Submitted) International Journal of Environmental Pollution and Remediation.

[21] Mende, M., Schwarz, D., Steinbach,C., Boldt, R. and Schwarz, S. (Submitted) Colloids and Surfaces A: Physicochemical and Engineering Aspects.

[22] Gellner, M. (2012) Masterarbeit 2012, IPF/TU Dresden.

\section{Submit or recommend next manuscript to SCIRP and we will provide best service for you:}

Accepting pre-submission inquiries through Email, Facebook, LinkedIn, Twitter, etc.

A wide selection of journals (inclusive of 9 subjects, more than 200 journals)

Providing 24-hour high-quality service

User-friendly online submission system

Fair and swift peer-review system

Efficient typesetting and proofreading procedure

Display of the result of downloads and visits, as well as the number of cited articles

Maximum dissemination of your research work

Submit your manuscript at: http://papersubmission.scirp.org/ 